\title{
Agricultura familiar e programas de desenvolvimento rural no Alto Jequitinhonha ${ }^{1}$
}

\author{
Eduardo Magalhães Ribeiro* \\ Flávia Maria Galizoni** \\ Luiz Henrique Silvestre *** \\ Juliana Sena Calixto**** \\ Thiago de Paula Assis $* * * * *$ \\ Eduardo Barbosa Ayres $* * * * * *$
}

Resumo: Os regimes agrários peculiares e os baixos níveis relativos dos indicadores sócio-econômicos fizeram com que a região do alto Jequitinhonha, nordeste de Minas Gerais, fosse considerada uma das mais complexas do Brasil. Por isso, vários governos orientaram para lá programas de desenvolvimento rural. Mas esses esforços não produziram bons resultados. Este artigo analisa as relações entre programas públicos e agricultura familiar, fazendo um balanço dos métodos e resultados das últimas três décadas. Conclui pela necessidade de incorporar as especificidades de história, ambientes e sociedade aos programas, que deveriam partir das experiências das organizações da região e se ajustar às ações e à cultura desses agricultores.

\footnotetext{
* Economista, professor associado da Universidade Federal de Lavras, pesquisador CNPq, do Núcleo de Pesquisa e Apoio à Agricultura Familiar (Núcleo PPJ/UFLA). eduardomr@ufla.br.

** Antropóloga, bolsista CNPq, do Núcleo PPJ/UFLA. flaviagalizoni@yahoo.com.br. *** Administrador, mestrando PPGAD/UFLA, bolsista CAPES, do Núcleo PPJ/UFLA. lhsilvestre@yahoo.com.br.

**** Engenheira florestal, mestranda PPGAD/UFLA, bolsista CAPES, do Núcleo PPJ/ UFLA. jujucalixto@yahoo.com.br.

***** Engenheiro agrônomo, mestre, doutorando CPDA/UFRRJ, bolsista CNPq, do Núcleo PPJ/UFLA. trassis@yahoo.com.br.

$* * * * * *$ Engenheiro agrônomo, da equipe técnica do Centro de Agricultura Alternativa Vicente Nica, de Turmalina, vale do Jequitinhonha. eduardoturmalina@yahoo.com.br. ${ }^{1}$ Este artigo é parcialmente baseado em pesquisas apoiadas pelo CNPq (520792/01-7, 504111/03-5 e 504665/04-9) e FAPEMIG (SHA 2876/97 e 941/2).
} 
Palavras-chave: agricultura familiar, desenvolvimento rural, extensão rural, programas públicos, vale do Jequitinhonha.

Classificação JEL: R58; Q15

Abstract: The agrarian conditions and the low relative levels of the socioeconomic indicators cause the area of the "High Jequitinhonha Valley", in the northeast of the State of Minas Gerais, to be considered one of the most complex areas of Brazil. For this reason several governanmental administrations have recommended rural development programs. Most of these efforts, however, have not produced adequate results. This article analyzes the relationships between public programs and family farming, making a survey of the methods and results of the last three decades. It concludes that there is a need to incorporate the specificities of history, environment and culture into the rural programs. It is suggested that the programs take into consideration the experience accumulated by the regional organizations and be adjusted to the interest and culture of the local family producers.

Key words: family farming, rural extension, rural development, public programs, Jequitinhonha Valley.

JEL Classification: R58; Q15

\section{O tema}

O vale do Jequitinhonha desafia os brasileiros desde os anos 70. Nessa época, os estudos para o planejamento destacaram os baixos níveis relativos dos seus indicadores sócio-econômicos, que desde então foi transformada na região da pobreza por excelência: passou a ser referência de atraso, exemplo de carência e, mais tarde, destino natural de programas compensatórios. Dos anos 1970 aos 2000 o Jequitinhonha foi alvo de programas de desenvolvimento rural e de inclusão social. A cada aflição numa seca, a cada estatística escabrosa, a cada mudança de governo estadual ou federal, eram propostas novas intervenções públicas; apesar disso, os indicadores continuaram quase os mesmos. Certamente há algum equívoco nos diagnósticos, nos programas ou nos seus métodos.

RER, Rio de Janeiro, vol. 45, no 04, p. 1075-1102, out/dez 2007 - Impressa em novembro 2007 
Eduardo Magalhães Ribeiro, Flávia Maria Galizoni, Luiz Henrique Silvestre, Juliana Sena Calixto, — 1077

Thiago de Paula Assis e Eduardo Barbosa Ayres

O objetivo deste artigo é analisar um aspecto particular dessas intervenções: as relações entre agricultores familiares e programas de desenvolvimento rural e compensatórios. Estes agricultores são expressivos em termos demográficos, econômicos e culturais na região, participam quase que somente de mercados locais e costumam ser designados na literatura técnica como camponeses ou agricultores tradicionais; serão designados neste artigo pelo termo que usam para se definir: lavradores, ou pela denominação adotada por seus dirigentes sindicais: agricultores familiares. São organizados em entidades que construíram - sindicatos de trabalhadores, ONGs, comissões, além dos fóruns de ação conjunta - que geralmente conseguem escapar dos dilemas municipais e clientelísticos da política local. $\mathrm{O}$ artigo procura compreender a lógica que norteou os programas públicos, seus descompassos e ajustes às especificidades desse rural. Por isso, antes de analisar resultados, analisa métodos; e como os programas foram muitos, foi necessário compreendê-los também numa perspectiva histórica.

\section{Metodologia}

Este artigo une resultados de pesquisas e atividades de extensão universitária feitas na última década por este grupo de pesquisa (Núcleo PPJ/UFLA) em parceria com organizações do alto Jequitinhonha - sindicatos de trabalhadores rurais, prefeituras, agências leigas e religiosas, ONGs -, particularmente junto com o Centro de Agricultura Alternativa Vicente Nica, CAV.

Atividades de extensão, como assessorias, seminários e dias-decampo, surgiram de demandas das organizações parceiras e foram feitas com o propósito de capacitar lavradores, lideranças e técnicos. Muitas vezes, nessas capacitações eram debatidos temas que se transformavam em projetos de pesquisas, que inseriam os pesquisadores nas comunidades rurais e fóruns regionais, cujos resultados implicavam em novas atividades de extensão. Em alguns casos, ações de pesquisa/extensão se transformaram em programas voltados, por exemplo, para recursos hídricos e feiras livres, e uniam organizações regionais e universidade em torno de temas comuns. Essa realimentação entre pesquisa e extensão estimulou trocas de conhecimentos, aproximou as perspectivas da equipe de pesquisadores e das organizações parceiras, permitindo que fosse amadurecida uma reflexão conjunta sobre programas regionais de 
desenvolvimento. Assim se chegou à investigação das relações entre população rural e programas públicos. ${ }^{2}$

As pesquisas que deram base ao artigo, feitas com o propósito de orientar ações ou corrigir seus rumos, trataram de população rural, recursos naturais, comercialização, organização social e cultura regional, e em sua maioria foram apoiadas por agências públicas de fomento. Com exceção de alguns levantamentos quantitativos, foram usadas técnicas qualitativas e fontes bibliográficas; destas, as mais utilizadas foram os diagnósticos, censos, planos de desenvolvimento, dissertações e teses sobre o rural da região. O emprego das técnicas qualitativas se explicava pelos objetivos das pesquisas: procuraram compreender as estratégias de reprodução construídas ou adaptadas pela população da região para viver neste rural. Por isso este artigo usa apenas dados secundários como fonte de informações quantitativas sobre esses lavradores, cujas estratégias carregam um forte componente cultural e ambiental. ${ }^{3}$

As pesquisas foram orientadas por quatro focos, que estruturam o artigo:

i. a família, a comunidade e o trabalho rural;

ii. a diversidade de cultura e ambiente no rural;

iii. a parceria com organizações do alto Jequitinhonha, que viabilizou a integração pesquisa/extensão universitária/pesquisa;

iv. a articulação com, e a participação nas, ações coletivas, públicas e redes sociais relacionadas ao desenvolvimento rural da região.

A família é o fundamento dessa sociedade rural: famílias se reúnem em comunidades, que articulam parentesco, ambiente, espaço e história para formar unidades de reprodução de cultura e técnica material, de trocas de bens e dons. Famílias e comunidade são depositárias de um histórico de convívio, aprendizado e experimentação que forma um acervo respeitável de conhecimentos sobre o meio. As pesquisas envolveram famílias e comunidades por meio de dinâmicas participativas como reuniões, caminhadas pelo espaço produtivo, mapeamentos de recursos naturais e agências mediadoras, entrevistas coletivas segmen-

${ }^{2}$ Sobre essas experiências de pesquisa e extensão ver Ribeiro e Galizoni (2003) e Ribeiro, Galizoni e Castro (2006).

${ }^{3}$ Sobre estratégias de reprodução de agricultores ver Brandão (1981), Garcia Jr (1991) e Abramovay (2004). 
Eduardo Magalhães Ribeiro, Flávia Maria Galizoni, Luiz Henrique Silvestre, Juliana Sena Calixto, — 1079

Thiago de Paula Assis e Eduardo Barbosa Ayres

tadas por sexo e idade para analisar costumes relacionados a trabalho, meio, técnicas e reprodução material. ${ }^{4}$

Foi, ainda, essencial compreender as estratégias de reprodução dessas famílias rurais à luz da diversidade de acesso aos recursos naturais. Elas vivem em estreita relação com o meio, e os nichos ambientais - áreas de campo, capão ou tabuleiro, por exemplo - exigem técnicas de manejo diferentes para sistemas produtivos específicos. Por isso o ambiente se tornou elemento constitutivo das pesquisas, já que sua diversidade informa a cultura material e define as características dessas muitas agriculturas. Nenhuma delas, porém, se integra a cadeias produtivas: à luz das categorias usadas pelo Programa Nacional de Fortalecimento da Agricultura Familiar, Pronaf/MDA, seriam consideradas "periféricas"; de outra perspectiva, fariam parte dessa categoria que os antropólogos têm denominado como "campesinato tradicional". Esses lavradores enfrentam entraves, mas criam habilidades; vivem fases de escassez, mas também de abundância. Neste texto as diversidades são analisadas como características, não como problemas, e foram fundamentais para analisar os programas implementados na região. ${ }^{5}$

As pesquisas, enfim, se orientaram pelas especificidades locais e procuraram incorporar experiências amadurecidas e costumes regionais às reflexões sobre desenvolvimento. No meio rural do alto Jequitinhonha existem muitas ações, governamentais ou não, como projetos públicos, programas compensatórios federais e estaduais, iniciativas de agências religiosas, instâncias supra-municipais de atuação em rede para geração de renda, capacitação, comercialização, economia solidária, conservação ambiental e educação rural. Desde meados dos anos 80 as organizações rurais da região se esforçam para participar dessas ações, ou para criar seus próprios programas de desenvolvimento regional. ${ }^{6}$

\footnotetext{
${ }^{4}$ Sobre técnicas participativas em pesquisas com populações rurais ver Posey (1987), Gomes e outros (2000) e Amorozo e outros (2002); sobre comunidades ver Cândido (1975), Galizoni (2002) e Comerford (2003); sobre família ver Chayanov (1974), Durham (1983) e Bruschini (1989); sobre ambiente e trabalho rural ver Brandão (1981) e Woortmann e Woortmann (1997).

${ }^{5}$ Sobre as categorias do Pronaf ver Abramovay (2004); sobre agricultura tradicional consultar Diegues (1996); sobre o rural do alto Jequitinhonha ver Graziano (1986), Ribeiro e Galizoni (2000) e Galizoni (2002).

${ }^{6}$ Sobre incorporação de cultura local a programas públicos consultar Contag (1999) e Abramovay (2003).
}

RER, Rio de Janeiro, vol. 45, no 04, p. 1075-1102, out/dez 2007 - Impressa em novembro 2007 
Mapa 1 - Minas Gerais, Alto e Baixo Jequitinhonha

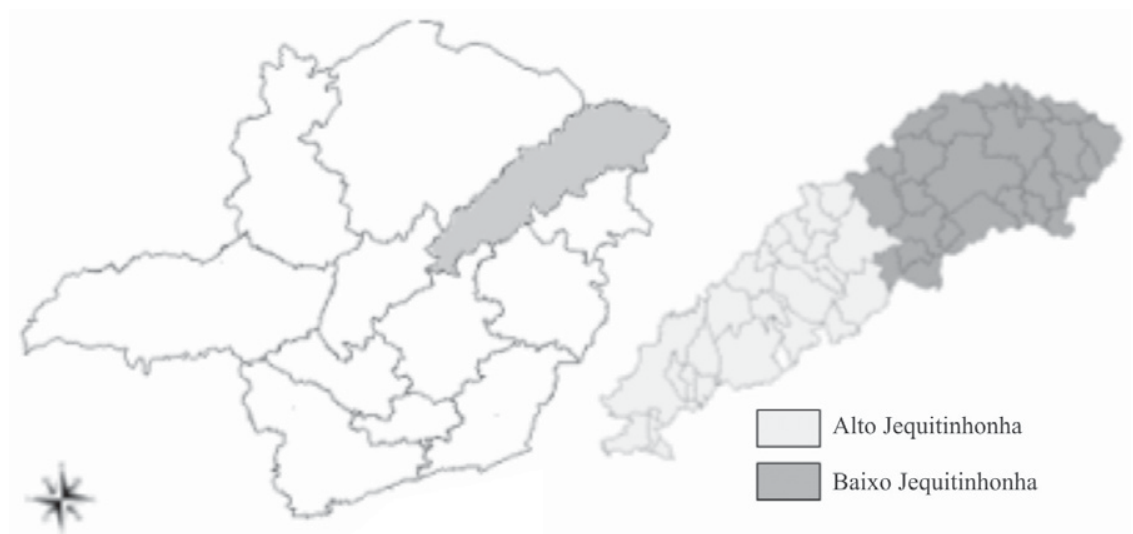

Fonte: Mapa Geopolítico de Minas Gerais - IGA/CETEC - 1994

Por fim, em face da diversidade espacial do vale do Jequitinhonha, este artigo usa um recorte territorial adaptado, baseado na história, cultura e estrutura fundiária. Assim, denomina alto Jequitinhonha à região marcada pela herança do ciclo minerador do século XVIII e pela agricultura familiar, situada acima da foz do rio Araçuaí; designa como baixo Jequitinhonha a região de domínio fazendeiro, entre a foz do Araçuaí e a divisa mineira com a Bahia (Mapa I).

Nas páginas seguintes o artigo traz uma breve caracterização da região; em seguida faz um histórico das relações entre programas públicos e agricultura familiar e, por fim, apresenta algumas conclusões sugeridas pela - e inspiradas na - caminhada dos grupos rurais organizados.

\section{O nascimento do Jequitinhonha}

O alto Jequitinhonha é coberto por cerrados, campos e vegetação de transição para mata atlântica ou caatinga. A paisagem é marcada por chapadas planas, com altitudes entre 800/1.000 metros, cortadas por vales profundos, as grotas. Chapadas e grotas se opõem e completam: a chapada é naturalmente pouco fértil, mas recebe entre 1.000/1.200 mm de chuvas anuais, enquanto na terra fértil da grota chove entre 600/800 $\mathrm{mm}$; nas grotas ficam os sítios, casas e lavouras dos lavradores, en- 
Eduardo Magalhães Ribeiro, Flávia Maria Galizoni, Luiz Henrique Silvestre, Juliana Sena Calixto, — 1081

Thiago de Paula Assis e Eduardo Barbosa Ayres

quanto a chapada é área de solta comum de animais e dos eucaliptais das empresas; nas chapadas existem os campos-sujos típicos do Cerrado, nas grotas estão os rios e a vegetação de porte elevado que indica boas terras para lavoura: culturões, partilhados entre famílias.

O Jequitinhonha entrou para os registros da história no século XVIII, quando era área de mineração exclusiva ou de concessão da Coroa portuguesa, o Distrito Diamantino, que por décadas sustentou a Metrópole, cuja fama atraiu viajantes que o descreveram para o mundo: Pohl, Saint-Hilaire, Spix e Martius. Mas minério, riqueza e fama se acabaram no século XIX, e o Jequitinhonha desapareceu da história que se escreveria. Veio então um longo período de estabilização e transumâncias, e enquanto famílias de lavradores se firmavam nas culturas das grotas, outra parte da população refluía para leste, rumo à vizinha mata atlântica do Mucuri e baixo Jequitinhonha. Nessa época um viajante definiu a região como um lugar de "farta mediania": não havia mais a exuberância da mineração, mas as pessoas dispunham do necessário para viver. Nos estudos sobre Minas Gerais nos começos do século XX, o Jequitinhonha seria parte de um vago "Norte", que o reunia ao Mucuri e São Francisco num amplo "sertão” desconhecido, meio baiano, uma das peças mais remotas do mosaico regional mineiro.?

A associação do Jequitinhonha com pobreza é recente, surgida nos anos 60/70, no tempo do milagre econômico e dos programas de desenvolvimento. Apareceu assim no Primeiro Plano Mineiro de Desenvolvimento, de 1971 - certamente o documento que inaugurou essa abordagem que se tornaria corriqueira -, por conta da baixa produtividade agrícola e da precariedade dos indicadores sociais. O método usado então era este: estudos para o planejamento recortavam regiões, identificavam desníveis sócio-econômicos e elegiam prioridades que fundamentavam os programas e a negociação dos recursos. O clamor objetivo dos dados - que mostravam participação modesta na produção e indicadores sociais abaixo da média mineira - sugeria intervenções e definia uma vocação produtiva para modernizar essa economia estagnada. ${ }^{8}$

\footnotetext{
${ }^{7}$ Ver Spix e Martius (1938), Saint-Hillaire (1975) e Pohl (1976); sobre história regional ver Pereira (1969), Santos (1976), Ribeiro (1996) e Furtado (1996); a expressão citada é de Celso (1981) e a idéia de mosaico de Wirth (1980).

${ }^{8}$ Sobre esses programas públicos e seus métodos ver Minas Gerais (1971), Diniz (1981), Haddad (1985) e Dulci (1999). A modernização, compreendida como alteração na com-
} 
Mas não foram apenas os dados, desfavoráveis, do alto Jequitinhonha que alicerçaram a construção dessa avaliação negativa. Antes, os dados deram suporte para a comparabilidade no estado, e diferenças se transformavam em problemas que deveriam ser eliminados para equalizar produtividade e renda nas diversas regiões. O Norte/Nordeste mineiro - e o alto Jequitinhonha em especial - foi construído assim como o lugar da pobreza: a expectativa de crescimento continuado que havia naqueles anos de milagre econômico estimulava as comparações e, nessa equalização, desaparecia a especificidade dessas regiões rurais. ${ }^{9}$

Ocorreu, também, que a modernização das décadas de 1960/1970 integrou mercados, proporcionou ganhos de escala, viabilizou grandes plantas industriais e concentrou produção. Com isso, as regiões que até então eram ilhas de produção autárquica passaram a competir em termos de custos e produtividade em mercados que se tornaram nacionais. As especificidades regionais se tornavam redundâncias desnecessárias à medida que mercados se integravam e autarquias desapareciam, o local ficava subordinado ao nacional e o alto Jequitinhonha deveria efetivamente ser classificado como pobre em termos relativos e absolutos, porque seria comparado ao dinamismo de outras regiões e porque sua sociedade rural se tornaria o resto de um passado que persistia. Seria transformado num problema, como o vale do Ribeira paulista, o centro paranaense e, mais especialmente, como o Nordeste brasileiro. ${ }^{10}$

\section{Programas rurais para o alto Jequitinhonha}

Partindo dessa concepção de pobreza e da expectativa de um crescimento econômico continuado, as agências públicas conduziram programas para a região. Como o lugar era considerado pobre - e, se supunha, vazio de iniciativas -, para minorar a pobreza seria necessário definir sua vocação produtiva, levar empresas para a região e animá-las

binação dos fatores produtivos, foi o principal objetivo dos planejadores da época; Furtado (1992) analisou suas conseqüências.

${ }^{9}$ Para uma análise da construção de tipos-ideais de regiões ver Andrade (1987) e Albuquerque Jr (2001).

${ }^{10}$ A integração das regiões mineiras foi analisada por Diniz (1981) e Dulci (1999); Sahlins (1978) analisou a pobreza como categoria relativa; sobre pobreza no Jequitinhonha ver Amaral (1988).

RER, Rio de Janeiro, vol. 45, no 04, p. 1075-1102, out/dez 2007 - Impressa em novembro 2007 
Eduardo Magalhães Ribeiro, Flávia Maria Galizoni, Luiz Henrique Silvestre, Juliana Sena Calixto, — 1083

Thiago de Paula Assis e Eduardo Barbosa Ayres

com subsídios. Para isso foi criada a Companhia de Desenvolvimento do Vale do Jequitinhonha (Codevale), abertas linhas de crédito rural e criados programas de apoio ao reflorestamento.

O fracasso da Codevale foi exemplar. Perdida entre a inanição de recursos públicos e o apetite de políticos, a população da região resumiu sua trajetória numa frase: "Nem aCode [ninguém], nem Vale [muita coisa]".

Já o crédito rural, naquele tempo, exigia beneficiários de renda elevada e mudanças na técnica produtiva para implantar a transformação agrícola que veio a ser conhecida como revolução verde. Isso criou uma barreira para a inclusão da maioria das famílias rurais da região, e assim modernização e crédito rural passaram ao largo dos sítios do alto Jequitinhonha. Até a agricultura patronal ficou de fora desses programas, pois enquanto houve subsídio as fazendas da região - fazendas fracas de recursos, como se diz lá - se desalentavam com a saída de moradores agregados para a capital de São Paulo e continuaram produzindo sem incorporar mudança técnica, num regime de trabalho denominado por macaco: os lavradores plantavam no tempo-das-águas em terras cedidas na meia e trabalhavam no tempo-da-seca em troca de alimentos, recebendo uma rapadura, ou meio quilo de toucinho ou uma medida de feijão-andu como paga por uma jornada de 12 horas. O crédito rural promoveu pouca mudança técnica nessas fazendas, com a exceção da cafeicultura de montanha implantada em alguns municípios da região. ${ }^{11}$

Os incentivos ao reflorestamento, concebidos para ocupar terras de chapadas, levar empresas para a região e criar empregos, promoveram a partir da segunda metade dos anos 70 a ocupação dessas áreas planas, até então usufruídas por comunidades rurais para coleta e pastoreio a solta nos campos. Essas terras foram apropriadas por empresas madeireiras, carvoeiras e de celulose por meios diversos: griladas, arrendadas ao Estado ou adquiridas a preço muito baixo. Na microrregião de Capelinha, bacias dos rios Fanado e Itamarandiba, as empresas plantaram com eucaliptos um terço da área agrícola total, 130 mil hectares de chapadas entre 1975/1980. Depois de um breve surto de geração de ocupação, que triplicou o emprego temporário entre 1975 e 1980, o número de empregos em

${ }^{11}$ A exclusão produtiva da revolução verde foi analisada por Delgado (1985), Grzybowski (1987) e Ferreira e outros (2001). Sobre programas modernizantes para o Jequitinhonha consultar Furtado (1985), Silva (1988), Moura (1988), Medeiros Silva (1990), Luz e Dayrell (2000), Freire (2001) e Ribeiro, Galizoni e Assis (2004).

RER, Rio de Janeiro, vol. 45, no 04, p. 1075-1102, out/dez 2007 - Impressa em novembro 2007 
1995 retornou ao patamar de 1975. Em 1995 as reflorestadoras criavam, na média, uma (1) ocupação para 83,33 hectares plantados em eucaliptos; na mesma microrregião os sítios familiares criavam uma (1) ocupação para 4,95 hectares e geravam renda anual por hectare cinco vezes maior. Além disso, eucaliptais foram responsabilizados por danos ambientais diretos: assoreamento de nascentes, destruição de áreas de recarga, secagem de lagoas; e indiretos, porque a concentração do pastoreio acentuou processos erosivos nas terras das grotas. Os reflorestamentos criaram nas comunidades rurais um sentimento de perda e sacrifício inútil.

A principal conseqüência dos programas de crédito e reflorestamento no alto Jequitinhonha não foi na técnica, na produção, no emprego ou na chegada de novos empresários, nem sequer na mudança das mentalidades. A grande transformação aconteceu na renda fundiária: as chapadas foram transformadas em ativos financeiros; a pressão por plantio de mantimentos nas terras férteis remanescentes das grotas fez com que as minúsculas áreas de culturas dos sítios se tornassem tão escassas em termos relativos que a renda cobrada pela cessão da terra nua para lavoura atinge um terço do volume bruto da produção. A revolução verde deixaria outras marcas, indiretas, na erosão genética das matrizes vegetais tradicionais contaminadas por linhagens híbridas exigentes em fertilidade e água, na imposição de um padrão técnico de cultivo agrícola, nas restrições ao comércio nos mercados regionais. ${ }^{12}$

A essência dos sistemas produtivos das comunidades rurais permaneceu. A produção continuou baseada em plantio de mantimentos, coleta, trabalho familiar e beneficiamento primário; a comercialização permaneceu periférica e quase que exclusivamente local. Na memória dos lavradores, a década de 1970 seria relacionada, sobretudo, à migração que deixara mais próximo São Paulo e tudo que a capital significava: construção civil, emprego, salário, registro de contrato em carteira de trabalho, monetarização, acesso a bens de consumo e, às vezes, compra de terras; às vezes! ${ }^{13}$

\footnotetext{
${ }^{12}$ Na região de plantio mais intenso de eucaliptos (Microrregião Homogênea de Capelinha) a agricultura de pequena escala ocupava $31,94 \%$ da área e gerava $88,11 \%$ das ocupações rurais, segundo o Censo de 1995/96. Sobre os impactos do eucalipto e da revolução verde na região ver Furtado (1985), Graziano (1986), Silva (1988), Moura (1988), Medeiros Silva (1990), Luz e Dayrell (2000) e Calixto (2006).

${ }^{13}$ Essas emigrações foram analisadas por Brito e Souza (1995) e Ribeiro, Galizoni e Assis (2004).
}

RER, Rio de Janeiro, vol. 45, no 04, p. 1075-1102, out/dez 2007 - Impressa em novembro 2007 
Eduardo Magalhães Ribeiro, Flávia Maria Galizoni, Luiz Henrique Silvestre, Juliana Sena Calixto, — 1085

Thiago de Paula Assis e Eduardo Barbosa Ayres

\section{O Jequitinhonha revisto}

Para o Brasil e para o alto Jequitinhonha, o contexto dos anos 80 foi outro: acabou o crescimento econômico e, já nos primeiros anos, a contração do mercado de trabalho urbano eliminou a principal alternativa de emprego para lavradores excluídos da terra. O Censo de 1985 mostraria o reverso desse fenômeno: a expansão do número de pequenos estabelecimentos familiares revelava um retorno ao rural, um renovado interesse por terra que culminaria nos movimentos que emergiriam uma década depois exigindo inclusão produtiva para aqueles que precisariam viver do campo. Os resultados contraditórios dos programas de desenvolvimento rural, a acentuação das desigualdades fundiárias, a fragmentação excessiva da terra dos sítios, a agonia da ditadura militar e o crescimento dos movimentos sociais rurais estimularam palavrasde-ordem como "reforma agrária" e "política agrícola para o pequeno produtor", que desde o final dos anos 70 eram propostas pela Confederação Nacional dos Trabalhadores da Agricultura (CONTAG) e Comissão Pastoral da Terra (CPT), da Igreja Católica.

Essas circunstâncias da década de 1980 propiciaram uma revisão crítica do estilo dos programas de desenvolvimento rural da revolução verde. Essa crítica seria incorporada por mediadores, pesquisadores, extensionistas e, por fim, pelas agências públicas, pois embora ocorressem saltos sucessivos de crescimento de produção e produtividade agrícola, a dúvida sobre a capacidade desse modelo de desenvolvimento distribuir benefícios seria cada vez mais sólida, já que a expansão produtiva baseada no tripé veneno-adubo-trator reproduzia no campo de quase todas as regiões os indicadores urbanos de concentração de renda, multiplicava os impactos ambientais negativos e acentuava a exclusão produtiva. A maturação dessa crítica à modernização da agricultura foi demorada e a construção de propostas alternativas foi marcada por muitos equívocos. Mas a crítica cresceu com vigor, o mesmo que os movimentos sociais rurais adquiriram a partir dos anos 80. À medida que as organizações sociais rurais fortaleciam experiências micro-locais e reuniam num mesmo debate produção, política e cultura, abririam oportunidade para repensar, mais favoravelmente, seus arranjos tradicionais e costumes de uso da terra. Foi daí que veio a reivindicação

RER, Rio de Janeiro, vol. 45, no 04, p. 1075-1102, out/dez 2007 - Impressa em novembro 2007 
de participação dos excluídos do campo na formulação de ações pelo desenvolvimento, porque seu conhecimento do local permitiria ajustar programas às demandas sociais, ao meio e aos recursos disponíveis. ${ }^{14}$

Essa foi uma parte da história rural dos anos 80 . No alto Jequitinhonha ela manifestar-se-ia no fortalecimento do movimento sindical dos trabalhadores rurais - apoiado pela CPT -, no enfraquecimento das lideranças políticas conservadoras e na proliferação das organizações de mediação. Movimento e mediadores se apoiaram em comunidades rurais, que formavam as Comunidades Eclesiais de Base, as CEBs católicas, que gerariam associações, comissões e, principalmente, os renovados Sindicatos de Trabalhadores Rurais, STRs. Na região os STRs organizaram lavradores e assumiram a condução de programas de formação política e conservação ambiental. À medida que eram abertos os canais de participação, construiriam seus instrumentos de ação e, ao lado das organizações religiosas e não governamentais, ganhariam fôlego para ousar influir nos programas de desenvolvimento rural. ${ }^{15}$

Dois estudos captaram essa revisão crítica. Em um, Eduardo Graziano (1986) questionava a suposta ineficiência da agricultura tradicional do Jequitinhonha, mostrando que a introdução dos reflorestamentos fragmentara as condições de reprodução, mas que os lavradores se reorganizavam nas grotas. Noutro estudo, Leila Amaral (1988) problematizava a recorrente associação entre pobreza e população rural da região, relativizando o conceito de "pobre" e indicando que, entre as alternativas de ocupação criadas com a modernização agrícola, a migração sazonal se transformara numa reação consistente, embora limitada, à desocupação estacional criada pelo sistema de lavoura.

Atividades comunitárias e sindicais, pesquisas e a revisão das ações públicas originadas do fortalecimento dos municípios depois da década de 1980, forçaram olhar o rural do alto Jequitinhonha sob outra perspectiva. Os dados sócio-econômicos mostravam uma região deprimida,

\footnotetext{
${ }^{14}$ Consultar sobre o assunto: CPT (1983; 1990); Grzybowski (1987); Martine e Garcia (1987); Martins e Perani (1992); Graziano da Silva (1996); Contag (1999); Brandenburg (1999); Almeida (1999) e Shiki (2000).

${ }^{15}$ Sobre comunidades e sindicalismo na região ver Amaral (1988), Alves e outros (1993) e Galizoni (2002); sobre CEBs e organizações de mediação consultar Frei Betto (1981), Silva (2004), Assis (2005) e Melo (2005).
} 
já que seus indicadores de renda, pobreza e analfabetismo continuaram inferiores aos valores médios apontados para Minas Gerais. Mas, eles precisariam ser compreendidos à luz das especificidades regionais, pois os dados gerais - como PIB agrícola, renda per capita, taxa de analfabetismo, escolaridade - revelam uma parte desse rural complexo, escondem outras e tornam necessário repensar a interpretação da pobreza e, principalmente, repensar o estilo dos programas de desenvolvimento.

Novas pesquisas mostraram uma sociedade rural com forte base comunitária, onde a família extensa domina as terras de grotas, estabelece áreas privativas e de uso comum e, ao mesmo tempo, define regras de gestão de terras e recursos. É um rural de comercialização reduzida, produção diversificada e população relativamente envelhecida, marcado pela cultura local. Os sistemas produtivos são, basicamente, autosuficientes: usam a força da terra e o manejo da vegetação para repor a fertilidade dos solos e a população rural satisfaz grande parte de suas necessidades alimentares com produção autônoma - comendo feijão de si mesmo, como definem -, apoiada por coletas sazonais nas terras altas e secas dos campos e carrascos que restaram apropriadas em comum. Nas lavouras não usam trator, veneno ou adubo, o mercado nacional de bens agrícolas não determina sua pauta produtiva e os programas modernizadores esbarram nos costumes, na cultura e nos regimes agrários. ${ }^{16}$

Essa sociedade rural se baseia, primeiro, no trabalho familiar - combina as forças plenas dos homens e mulheres adultos às forças "periféricas” de idosos e jovens - orientado para reproduzir e conservar a unidade de produção, desafiando a escassez material e a fragmentação da terra. Segundo, apóia-se num vasto conhecimento dos recursos naturais, que orienta as decisões sobre o que, onde e quando plantar, quais recursos utilizar, e como. Terceiro, cria sistemas de gestão comunitária, que governa, partilha e conserva recursos, com base no conhecimento do meio, na espacialidade comum e em acordos familiares, permitindo que, na região, o uso intenso do solo conviva com a maior cobertura percentual de vegetação nativa manejada de Minas Gerais. ${ }^{17}$

\footnotetext{
${ }^{16}$ Bloch (2001) define regime agrário como o conjunto de regras costumeiras que regulam trabalho, uso da terra e recursos naturais num território específico.

${ }^{17}$ Sobre o rural da região ver Graziano (1986), Ribeiro (1996), Ribeiro e Galizoni (2000), Galizoni (2002) e Noronha (2003); sobre recursos comuns consultar Freire (2001), Ribeiro e Galizoni (2003), Ribeiro e outros (2005); sobre indústria doméstica rural e ar-
} 
Os sistemas de produção são tão ajustados a determinado local que as técnicas de cultivo e coleta variam até entre comunidades vizinhas. Eles combinam:

1) uso de técnicas ambientalizadas para plantio de mantimentos resistentes à seca, como os feijões andu, de corda e gurutuba;

2) coleta regular de frutos, essências, combustíveis e madeiras nas áreas comuns;

3) comercialização em pequena escala nas feiras livres e mercados locais;

4) indústria doméstica rural produtora de derivados de cana-deaçúcar, milho e mandioca.

Contando ainda com as redes comunitárias de solidariedade, essas famílias atravessam intempéries quase sem abalos - mesmo secas muito fortes, como a que ocorreu no inverno de 2003 - porque as rendas monetárias vindas de bolsas, aposentadorias e emigrações sazonais permitem diversificar e estabilizar suas estratégias de reprodução.

Mas, é um equívoco afirmar que esses lavradores vivem na abundância; seria um engano tão grande quanto supor que estavam no paroxismo da pobreza. Pobreza é um conceito impreciso para definir sua condição, porque confunde essa com outras populações - particularmente aquelas que não dispõem de recursos naturais para reprodução - e elide os mecanismos específicos que reproduzem a situação de exclusão.

Constatada, então, a particularidade da sociedade rural e dos sistemas produtivos do alto Jequitinhonha, duas questões passaram a ser debatidas: para haver desenvolvimento seria realmente necessário intensificar a produção nesse rural? E se a experiência histórica indicava que esse rural não se moderniza no estilo e no ritmo perseguido por tantos programas públicos, seria justificável continuar alocando recursos materiais e humanos para estimular modernização?

\section{Três estilos de programas}

A partir dos anos 90 cresceu a diversidade de programas de desenvolvimento rural para o alto Jequitinhonha, com a persistência de

tesanato consultar Fernandes Filho e Campos (2003), Oliveira (2000) e Angulo (2002); sobre vegetação manejada ver Cemig (1993).

RER, Rio de Janeiro, vol. 45, no 04, p. 1075-1102, out/dez 2007 - Impressa em novembro 2007 
Eduardo Magalhães Ribeiro, Flávia Maria Galizoni, Luiz Henrique Silvestre, Juliana Sena Calixto, 1089

Thiago de Paula Assis e Eduardo Barbosa Ayres

alguns, o aprofundamento de outros, e ainda a inovação da gestão pública em outros. Destes, os que atingem direta ou indiretamente aos lavradores podem ser agrupados em três categorias: a) os programas modernizantes de grande escala que permaneceram; b) os programas específicos para agricultura familiar que foram aprofundados; c) os programas de gestão participativa, inovadores das políticas públicas.

Os programas modernizantes de grande escala, liderados principalmente pelo governo mineiro, permaneceram embalados pela mesma perspectiva dos anos 70: criar empregos temporários, elevar a produtividade, explorar intensivamente os recursos naturais. A novidade, certamente, é que o setor público reduziu suas despesas diretas, e mais financia que subsidia reflorestamentos e grandes barragens. Mas o método para eliminar a estagnação permanece o mesmo, pois busca erradicar, ao mesmo tempo, os indicadores de pobreza e o suposto pobre rural, seja por inundação, por falta de água ou pela tomada de terras; faz isto ao expulsá-lo para outras regiões - como fez a Usina Hidrelétrica de Irapé, no rio Jequitinhonha, que reassentou os atingidos pela barragem no Norte mineiro e no alto rio Doce; fazem isso as reflorestadoras ao desmatar áreas de recarga e secar as nascentes comunitárias; fazem isso os parques florestais, implantados depois da desapropriação de terrenos familiares. Esses programas colidem com os interesses dos lavradores, mas, ao contrário dos anos 70, muitas vezes as organizações da região conseguem dar respostas concretas quando seus interesses são prejudicados.

Os programas específicos para agricultura familiar promovem transferência de renda ou estimulam a produção. Surgiram na década de 1970, concebidos inicialmente para paliar os efeitos negativos da modernização agrícola nas regiões consideradas periféricas, por meio da distribuição de benefícios como equipamentos produtivos para melhoria da infra-estrutura comunitária e assistência social. No começo abarcavam grande número de prioridades e envolviam muitas agências públicas; nos anos 80 esses programas foram redesenhados, passando a ter um elenco reduzido de prioridades e agências, agindo pontualmente nas comunidades, geralmente sob a coordenação da Emater/MG ou da Secretaria Estadual do Trabalho. Depois, a universalização dos direitos previdenciários nos anos 90 estendeu aposentadorias e pensões à população rural, relativamente envelhecida pela emigração definitiva de 
jovens e pela imigração de retorno de trabalhadores urbanos. O Pronaf, surgido nos anos 90, criado com o propósito de estimular a produção, aumentou bastante sua presença no Jequitinhonha depois dos anos 2003/2005, principalmente nos municípios onde a Emater/MG é mais ativa. Finalmente, nos anos 2000, as transferências em dinheiro (bolsas e, depois, Bolsa Família) atingiram grande parte dessas famílias rurais.

Esses programas criaram benefícios duradouros. Colocaram equipamentos de beneficiamento à disposição das comunidades rurais - as denominadas fabriquetas comunitárias - que reduziram a penosidade do trabalho, aumentaram a produção, a produtividade e a renda familiar pela agregação de valor a uma pauta produtiva tradicional vendida no comércio local: farinhas de milho e mandioca, polvilho, mel, rapadura, açúcar-mascavo e cachaça. Aposentadorias e pensões elevaram - ou criaram, onde não havia - rendas monetárias; dando mais liquidez às famílias com terra, estimularam o comércio urbano e o consumo dos produtos tradicionais da lavoura e da indústria doméstica nas feiras livres. Mas essas rendas influenciam também a produção, pois famílias rurais com rendas de transferências respondem por boa parte da produção comercializada em feiras municipais, e lavradores que recebem transferências ficam com maior segurança econômica para acessar créditos do Pronaf. Ficou, portanto, sutil a distinção entre programas de estímulo à produção e de transferências de rendas: lavradores preferem o Pronaf não apenas pelo apoio produtivo, mas também pela renda que seu subsídio proporciona; as aposentadorias rurais apóiam a produção agrícola, além de transferir rendas. Assim, programas compensatórios se tornaram também programas produtivos, criando na região um dinamismo econômico mais denso, distributivo e duradouro, por exemplo, que os subsídios alocados em reflorestamentos ou barragens. ${ }^{18}$

Por fim, os programas de gestão compartilhada. Nos anos 80 eles foram experimentados em iniciativas públicas como o Programa de Apoio

\footnotetext{
${ }^{18}$ Ver literatura citada em nota anterior sobre indústria rural; sobre aposentadorias na região ver Augusto (2003); as iniciativas produtivas comunitárias foram analisadas por Melo (2005) e Assis (2005); sobre impactos municipais de programas compensatórios ver Ribeiro e outros (2006). Pós-2003 o Bolsa-Família criou uma situação nova: com o pagamento por cartão, os beneficiários se consideram vinculados ao governo federal como um direito cidadão adquirido - e livres da tutela do político local; este, passou a ser responsabilizado apenas pelos descredenciamentos.
}

RER, Rio de Janeiro, vol. 45, no 04, p. 1075-1102, out/dez 2007 - Impressa em novembro 2007 
Eduardo Magalhães Ribeiro, Flávia Maria Galizoni, Luiz Henrique Silvestre, Juliana Sena Calixto, — 1091

Thiago de Paula Assis e Eduardo Barbosa Ayres

ao Pequeno Produtor (PAPP), que demandava participação comunitária na eleição de prioridades de ação. Depois, nos anos 90, veio o Pronaf Infra-estrutura, que inovou ao transformar, às vezes com enormes dificuldades, beneficiários em co-gestores. Sindicatos de Trabalhadores Rurais e organizações locais passaram a influir no uso e controle dos recursos do programa, mesmo que parcialmente. Embora na maior parte das vezes ocorresse prefeiturização da infra-estrutura adquirida, pronafear um neologismo criado por lavradores conselheiros de desenvolvimento - instituiu a participação nesses programas como uma necessidade.

Novos programas específicos procuraram compatibilizar participação e captação de demandas locais, compartilhando a gestão entre lavradores, sociedade civil e setor público. Nesse espírito foram criados os programas de Desenvolvimento Territorial (Ministério do Desenvolvimento Agrário, MDA), Mesoregiões (Ministério da Integração Nacional, MIN) e Consórcio de Segurança Alimentar e Desenvolvimento (Consad, Ministério do Desenvolvimento Social, MDS), por exemplo, todos eles supra-municipais. Sindicatos, ONGs, administrações municipais, organizações comunitárias e religiosas negociam seus objetivos nesses espaços políticos. Ultrapassar os limites municipais reduziu a influência das prefeituras sobre os programas, que ficaram menos permeáveis às pressões e mudanças de administração; a participação da sociedade civil conduziu à repactuação de objetivos, redirecionou gastos e, principalmente, exigiu uma avaliação dos equívocos passados. Este, certamente, é o maior mérito desses programas: ativar a memória social para inibir a repetição de aventuras.

Mas no alto Jequitinhonha esses programas participativos enfrentam problemas: a superposição de ações, as diferentes experiências dos participantes e a liberação dos recursos.

À parte pequenas variações no controle e implementação, programas participativos têm modelagem semelhante: pactuam objetivos entre prefeituras, órgãos públicos e organizações da sociedade civil, levantam demandas, elegem prioridades, selecionam beneficiários, definem investimentos, captam recursos, executam. A superposição torna-se um problema porque as agências governamentais concebem muitos desses programas ao mesmo tempo, sem qualquer articulação entre si, voltados para a mesma região e público-alvo quase idêntico. Em 2004/2005

RER, Rio de Janeiro, vol. 45, no 04, p. 1075-1102, out/dez 2007 - Impressa em novembro 2007 
um levantamento do MDS/FAO apontava que estavam em execução no Jequitinhonha os seguintes programas: Território (MDA), Fome Zero (MDS), Mesoregiões (MIN), Consad (MDS), CRSAN (apoiado pelo MDS), Programa Um Milhão de Cisternas (P1MC, apoiado pelo MDS); além disso, não estavam concluídos os Fóruns de Desenvolvimento Local Integrado e Solidário (DLIS), os compromissos de investimento do Pronaf Infra-Estrutura estavam em suspenso, e o Banco do Brasil ensaiava um programa de apoio à agroindústria. Esses programas, com áreas de abrangência apenas discretamente diferentes, envolviam as mesmas organizações, quase todas com base na agricultura familiar. Dessa forma, qualquer Sindicato, prefeitura ou ONG da região participava em, pelo menos, três desses programas originários de ministérios ou secretarias diferentes, mas com calendários, objetivos e metodologias muito semelhantes. A falta de articulação e entendimento entre agências estaduais e federais, a ausência de complementaridade entre programas, a superposição de temas e públicos esgotava, fisicamente até, o capital social da região: cada organização deveria enfrentar muitas reuniões, encaminhar propostas e arcar com o desgaste da criação de expectativas nas suas bases quando fazia levantamentos de demandas. ${ }^{19}$

Esses programas são prejudicados também pelas diferenças de experiências e métodos dos participantes, que dificulta acordos entre as organizações. Prefeituras têm as divisas municipais como limites de ação e raramente buscam sinergias com municípios próximos: não se unem pelas semelhanças, mas se afastam por suas diferenças e pelo pudor em estimular comparações entre prefeitos, que nada ganham com inimizades na vizinhança, mas perderiam muito se expusessem diferenças nesses fóruns. ${ }^{20}$ As organizações da sociedade civil e agências públicas de

\footnotetext{
${ }^{19}$ Consultar FAO/MDS (2005). Um exemplo de superposição ocorreu entre 2004/2006, quando foram implantados ou planejados para pequenas cidades da região três programas simultâneos de inclusão digital: um para garimpeiros, outro para agricultores familiares, outro para populações excluídas; cada um dispunha de recursos, equipes, prédios e equipamentos próprios e, evidentemente, era exibido como obra exemplar pela agência pública que o implantava.

${ }^{20} \mathrm{Na}$ região, associações de municípios funcionam apenas para mediação política com agências e secretarias estaduais; quando muito, gerem em conjunto equipamentos mecânicos. Nos programas participativos as prefeituras buscam mais repartir eventuais benefícios - como fazem nas associações - que reunir esforços para ações conjuntas.
} 
Eduardo Magalhães Ribeiro, Flávia Maria Galizoni, Luiz Henrique Silvestre, Juliana Sena Calixto, a 1093

Thiago de Paula Assis e Eduardo Barbosa Ayres

atuação regional que participam desses programas costumam ter experiências de negociação mais amplas que as prefeituras. Mesmo quando vêm de uma filiação espacial bem definida - ONG ou Emater de certo município, por exemplo -, elas são, quase sempre, obrigadas a atuar em rede para se legitimar. Como essas organizações não têm públicos exclusivos, operam em regime de competição acirrada e têm um horizonte de ação que ultrapassa os quatro anos de um mandato, precisam conquistar recursos, legitimidade, base territorial e construir referências de espaço físico e político maiores que um município. Nesse ponto sempre há choque: de um lado as perspectivas territoriais ampliadas das organizações da sociedade civil e de agências estatais; de outro, as perspectivas espaciais e temporais restritas das prefeituras. O conflito se resolve com a aprovação de propostas mais amplas nas plenárias de fóruns, derrubadas nos bastidores pelas prefeituras.

Mas, ao final, todos acabam sendo derrotados pelos entraves ou cortes na liberação dos recursos. Como a maior parte dos investimentos deverá ser feita pelo governo estadual ou federal, o andamento dos programas se estrangula quando esbarra em tramitações intermináveis, liberações intermitentes, investimentos adiados ou, no limite, em cortes orçamentários unilaterais que tornam desperdiçado o tempo gasto em negociações, esgotam a paciência dos beneficiários, comprometem o prestígio dos mediadores e liquidam com a credibilidade do programa.

\section{Conclusão: algumas sugestões para novas escolhas}

Três décadas de insucessos aconselham pensar novos horizontes para os programas de desenvolvimento rural do alto Jequitinhonha. A história revela que há muitas ilusões e, seguramente, ocorreram desperdícios de recursos nessas propostas modernizadoras de grande escala, que não apresentaram resultados semelhantes àqueles observados em outras regiões de Minas Gerais, como nos cerrados do Noroeste e Alto Paranaíba, onde incentivos públicos criaram uma agricultura intensiva. A experiência do rural do alto Jequitinhonha aponta para duas certezas: i) a produtividade física dos sistemas agrícolas adaptados à região é baixa; ii) essa produtividade, definitivamente, não cresce com os recursos técnicos da revolução verde porque existem barreiras de várias ordens: topográficas à 
mecanização, financeiras à química agrícola, culturais às técnicas intensivas, orçamentárias aos créditos rurais, ambientais à irrigação em larga escala. A baixa produtividade é uma característica estrutural do sistema, e não pode ser eliminada dentro do paradigma trator-adubo-veneno.

Em um artigo dos anos 90, Celso Furtado apontava alternativas para as calamidades da modernização, quando notava que a civilização pós-revolução industrial às vezes impunha escolhas: um bem-estar generalizado com níveis modestos de consumo ou um consumo elevado beneficiando parte menor da população, que deixava a maioria vegetando na pobreza. Furtado sugeria adaptar os programas de desenvolvimento às características regionais e, se fosse o caso, pensá-los para níveis modestos de renda e padrões de consumo baseados em referências especificamente locais. ${ }^{21}$

Por este caminho é possível pensar novos horizontes, ao mesmo tempo mais modestos e mais incluidores, para o desenvolvimento rural do alto Jequitinhonha: programas de baixo custo, descentralizados, ajustados à escala de operação técnica e cultural dos lavradores da região. A experiência acumulada revela que houve extraordinário efeito concentrador de terra e renda nos grandes empreendimentos rurais; revela que poucos recursos distribuídos para gestão descentralizada e postos à disposição desses lavradores alavancaram sua capacidade de auto-sustentação; revela que as organizações locais e regionais têm condições de gerir esses programas. Novos programas devem incorporar essa experiência acumulada, considerar a possibilidade de inovar a partir das tradições e, sobretudo, se apoiar em características do sistema produtivo que geralmente são consideradas distorções: a terra partilhada, o trabalho familiar, a lavoura adaptada, os mercados locais, a produção de pequena escala.

Esses sistemas produtivos fazem parte dessa realidade, são dados e não distorções. E eles podem ser melhorados, a partir deles podem ser construídos programas que elevam o nível de bem-estar para a maioria dessa população rural. Existem bons exemplos de melhoria da produtividade e da renda para além dos limites da revolução verde: nos incentivos à indústria doméstica rural tradicional, no emprego de sistemas

\footnotetext{
${ }^{21}$ Consultar Furtado (1992); ver também Kliksberg (2002), e Sachs (1986); este, nota que desenvolvimento não significa obrigatoriamente consumo afluente e estoques elevados de bens materiais.
}

RER, Rio de Janeiro, vol. 45, no 04, p. 1075-1102, out/dez 2007 - Impressa em novembro 2007 
Eduardo Magalhães Ribeiro, Flávia Maria Galizoni, Luiz Henrique Silvestre, Juliana Sena Calixto, — 1095

Thiago de Paula Assis e Eduardo Barbosa Ayres

agroflorestais, na retomada e uso alternativo das terras de chapadas. A indústria doméstica melhorada pelos programas de fabriquetas dos anos 80/90 responde na região por um produto agrícola de valor superior àquele gerado pelas reflorestadoras em centenas de milhares de hectares de chapadas. Sistemas agroflorestais, combinando produção de alimentos e conservação ambiental, são usados com sucesso em dezenas de comunidades da região. A retomada das terras de chapadas seria, já, uma reparação histórica: tornaria desnecessária a migração sazonal de lavradores para se patrimonializar e adquirir terras no próprio Jequitinhonha, reduziria a partilha excessiva das terras de grotas, corrigiria a distorção que é o uso das terras públicas por reflorestadoras, e, até, tornaria viável criar novas possibilidades produtivas nessas áreas de campos.

Sem enveredar para um otimismo excessivo, é possível notar que algumas das alegadas dificuldades técnicas e econômicas da região apresentam aspectos positivos: rendas de aposentadorias e pensões têm a faceta virtuosa de estimular a produção agrícola, a indústria rural familiar e potencializar mercados locais; a lavoura rústica é matriz para uma agricultura inteligente e conservacionista que privilegia a heterogeneidade dos agroambientes e a reciclagem de recursos naturais; o agroextrativismo gera renda, estimula a gestão local de recursos, valoriza a identidade, o sentimento de pertencimento e a soberania alimentar; as migrações sazonais carreiam para a região uma poupança significativa, sofrida, mas constante. É evidente que pensar programas de desenvolvimento a partir dessas supostas distorções econômicas recoloca novas questões, por exemplo: a modéstia dos fluxos de renda da e para a região, a ausência de pesquisas sistemáticas sobre sistemas produtivos adaptados, o horizonte limitado dos pequenos projetos comunitários, a qualificação precária do pessoal técnico de extensão rural e pesquisa agropecuária - que quase sempre ignora cultura, manejo, ambiente e normas de gestão dessas populações rurais. Mas, de outro lado, também é preciso ponderar: qual futuro os grandes projetos modernizantes ofereceram para essa população rural?

Falta muito, ainda, para ocorrer uma mudança na maneira como mineiros e brasileiros, em geral, tratam o Jequitinhonha. A mística da pobreza - não importa se no paroxismo, na estatística ou no cotidiano das pessoas - sempre serve a oportunismos de veteranos e novatos na política, e obras, grandes ou pequenas, são pontes fáceis para visibilidade 
eleitoral. Programas públicos são implementados mais rapidamente se oferecem boas perspectivas de negócios, se forem pautados por métodos padronizados de ação que tornam seu controle mais simples e seus resultados mensuráveis. Por isso continuam a ser formulados programas nãoespecíficos, genéricos de grande amplitude, que pretendem ser o remédio para o alto e o baixo Jequitinhonha, o Nordeste, o Ribeira e a periferia de São Paulo; para os territórios, os famintos e as mesoregiões.

Mas esses lavradores, sindicalistas, agentes e mediadores da região têm uma grande dose de bom senso. Eles recebem novos programas públicos escudados na paciência, na sutileza, na experiência; armados, já, com os mesmos recursos que usam para enfrentar secas, quebras de safra, falta de dinheiro. Aprenderam a conviver com isso - diriam os animadores do Programa Um Milhão de Cisternas - e vão se defendendo das velhas ilusões que sempre vem junto com os novos programas de desenvolvimento.

\section{Referências bibliográficas}

ABRAMOVAY, R. O futuro das regiões rurais. Porto Alegre, Editora UFRGS, 2003.

ABRAMOVAY, R. Laços financeiros na luta contra a pobreza. SP, AnnaBlume/Fapesp, 2004.

ALBUQUERQUE JR., D.M. A invenção do Nordeste. 2a . Edição. Recife: FJN, Editora Massangana; São Paulo, Cortez, 2001.

ALMEIDA, J. A construção social de uma nova agricultura. Porto Alegre, Editora da UFRGS, 1999.

ALVES, M.A., MOURA, M.M., LACERDA, S., ARAÚJO, M.T., COVO, P.E., GRAZIANO, E. Vicente fala: uma mão na terra outra no coração. Rio de Janeiro, AJUP, 1993.

AMARAL, L. "Do Jequitinhonha aos canaviais.” Belo Horizonte, dissertação (MS), Fafich/UFMG, 1988.

AMOROZO, M.C.M., MING, L.C. e SILVA, S.M.P. Métodos de coleta e análise de dados em etnobiologia, etnoecologia e disciplinas correlatas. Rio Claro, UNESP/SBEE, 2002. 
Eduardo Magalhães Ribeiro, Flávia Maria Galizoni, Luiz Henrique Silvestre, Juliana Sena Calixto, 1097

Thiago de Paula Assis e Eduardo Barbosa Ayres

ANDRADE, M.C. de Espaço, polarização e desenvolvimento. SP, Atlas, 1987.

ANGULO, J.L.G. "Feira e desenvolvimento local: o caso de Turmalina, vale do Jequitinhonha, MG" Lavras, dissertação (MS), PPGA/UFLA, 2002.

AUGUSTO, H.A. "Aposentadorias rurais e desenvolvimento municipal: o caso de Medina, Nordeste mineiro.” Lavras, dissertação (MS), PPGA/ UFLA, 2003.

ASSIS, T.P. "Agricultura familiar e gestão social: ONGs, poder público e participação na construção do desenvolvimento." Lavras, dissertação (MS), PPGA/UFLA, 2005.

BLOCH, M. A terra e seus homens. Bauru, Edusc, 2001.

BRANDÃO, C.R. Plantar, colher, comer. Rio de Janeiro, Graal, 1981.

BRANDENBURG, A. Agricultura familiar, ONGs e desenvolvimento sustentável. Curitiba, Editora da UFPR, 1999.

BRITO, F. e SOUZA, J. de. "Os emigrantes: Minas no contexto das migrações internas no Brasil.” Diamantina, Anais do VII Seminário sobre a Economia Mineira, 1995.

BRUSCHINI, M.C. Uma abordagem sociológica da família. Revista Brasileira de Estudos de População. V.6, número 1, jan/jul 1989.

CALIXTO, J.S. "Reflorestamento, terra e trabalho: análise da ocupação fundiária e da força de trabalho no alto Jequitinhonha, MG." Lavras, dissertação (MS), PPGAD/UFLA, 2006.

CÂNDIDO, A. Os parceiros do Rio Bonito. Terceira edição. São Paulo, Duas Cidades, 1975.

CELSO, A. Oito anos de parlamento: poder pessoal de D. Pedro II. Brasília, UNB, 1981.

CEMIG. "EIA-RIMA da UHE de Irapé". Belo Horizonte, mimeog., 1993.

CHAYANOV, A.V. La organización de la unidad económica campesina. Buenos Aires, Nueva Visión, 1974.

RER, Rio de Janeiro, vol. 45, no 04, p. 1075-1102, out/dez 2007 - Impressa em novembro 2007 
COMERFORD, J.C. Como uma família. Rio de Janeiro, Relume Dumará, 2003.

CONTAG: Confederação Nacional dos Trabalhadores da Agricultura. Desenvolvimento rural sustentável. Anais do I Fórum Contag de Cooperação Técnica, Brasília, 1999.

CPT/Comissão Pastoral da Terra. CPT: pastoral e compromisso. Petrópolis, Vozes, 1983.

CPT/Comissão Pastoral da Terra. Compromisso eclesial e político da Comissão Pastoral da Terra. Cadernos de estudos CPT número 2. São Paulo, Loyola, 1990.

DELGADO, G.C. Capital financeiro e agricultura brasileira. São Paulo/ Campinas, Ícone/Edunicamp, 1985.

DIEGUES, A.C. O mito moderno da natureza intocada. São Paulo, Hucitec, 1996.

DINIZ, C.C. Estado e capital estrangeiro na industrialização mineira. Belo Horizonte, UFMG/PROED, 1981.

DULCI, O.S. Política e recuperação econômica em Minas Gerais. Belo Horizonte, Editora UFMG, 1999.

DURHAM, E.R. “A família e a mulher.” SP, Cadernos CERU, número 18, $1_{\text {a }}^{\text {a }}$ série, maio de 1983 .

FAO/MDS. "PROJETO FAO TCP/BRA/2905: Programa de estudos em segurança alimentar e nutricional no âmbito dos CONSADs da região Sudeste.” Brasília, FAO/MDS, 2005.

FERNANDES FILHO, J.F. e CAMPOS, F.R. "A indústria rural no Brasil" Revista de Economia e Sociologia Rural. 41 (4) Nov/Dez 2003.

FERREIRA, B., SILVEIRA, F.G., GARCIA, R.C. "A agricultura familiar e o PRONAF: contexto e perspectivas.” GASQUES, J.G., CONCEIÇÃO, J.C. (orgs.) Transformações da agricultura e políticas públicas. Brasília, IPEA, 2001.

FREIRE, A.G. "Águas do Jequitinhonha." Lavras, dissertação (MS), PPGA/UFLA, 2001. 
Eduardo Magalhães Ribeiro, Flávia Maria Galizoni, Luiz Henrique Silvestre, Juliana Sena Calixto, • 1099

Thiago de Paula Assis e Eduardo Barbosa Ayres

FREI BETTO. O que é Comunidade Eclesial de Base. São Paulo, Brasiliense, 1981.

FURTADO, C. "O subdesenvolvimento revisitado". Campinas. Economia e Sociedade, 1, ago/1992

FURTADO, D.B.”Posseiros e despossuídos.” Belo Horizonte, dissertação (MS) FAE/UFMG, 1985.

FURTADO, J.F. O livro da capa verde: o regimento Diamantino de 1771 e a vida no Distrito Diamantino no período da Real Extração. São Paulo, Annablume, 1996.

GALIZONI, F.M. "Terra, ambiente e herança no alto Jequitinhonha, MG”. Revista de Economia e Sociologia Rural. 40(3) jul/set, 2002.

GARCIA JÚNIOR, A.R. O sul, caminho do roçado. São Paulo, Marco Zero, 1991.

GRAZIANO, E. "A arte de viver na terra - as condições de reprodução camponesa no vale do Jequitinhonha.” Itaguaí, dissertação (MS), CPGDA/ UFRRJ, 1986.

GRAZIANO DA SILVA, J.F. A nova dinâmica da agricultura brasileira. Campinas, IE/Unicamp, 1996.

GOMES, M.A.O; SOUZA, A.V.A e CARVALHO, R.S. "Diagnóstico Rápido Participativo (DRP) como mitigador de impactos sócio-econômicos em empreendimentos agropecuários." Belo Horizonte, Informe Agropecuário, vol. 21, $\mathrm{n}^{\circ}$ 202, jan/fev. 2000.

GRZYBOWSKI, C. Caminhos e descaminhos dos movimentos sociais no campo. Rio de Janeiro, FASE, 1987.

HADDAD, P. R. Dimensões do planejamento estadual no Brasil: análise de experiências. Rio de Janeiro, IPEA, 1985.

KLIKSBERG, B. "Dez falácias sobre os problemas sociais da América Latina." Revista de Administração Pública 36(3), maio/junho 2002.

LUZ, C. e DAYRELL, C. Cerrado e desenvolvimento: tradição e atualidade. Montes Claros, CAA/Rede Cerrado, 2000.

RER, Rio de Janeiro, vol. 45, no 04, p. 1075-1102, out/dez 2007 - Impressa em novembro 2007 
MARTINE, G. e GARCIA, R.C. (orgs) Os impactos sociais da modernização agrícola. São Paulo, Caetés, 1987.

MARTINS, J. S. e PERANI, C. Sonhos e desejos dos lavradores. Cadernos de estudos CPT, número 2. São Paulo, Loyola, 1992.

MEDEIROS SILVA, N. de. "Vale do Jequitinhonha: incorporação e transformações estruturais”. IN NABUCO, M.R. (org) Contradições do desenvolvimento agrícola de Minas Gerais uma perspectiva regional. Belo Horizonte, CEDEPLAR/UFMG, 1990.

MELO, A.P.G. "Agricultura familiar e economia solidária: a experiência em gestão de bens comuns e inserção em mercados por organizações rurais de Minas Gerais.” Lavras, dissertação (MS), PPGA/UFLA, 2005.

MINAS GERAIS/Governo Rondon Pacheco. "Plano Mineiro de Desenvolvimento Econômico e Social.” Belo Horizonte, Imprensa Oficial, 1971.

MOURA, M.M. Os deserdados da terra. Rio de Janeiro, Bertrand do Brasil, 1988.

NORONHA, A.G.B. "O tempo de ser, fazer e viver: modo de vida das populações rurais do alto Jequitinhonha, MG.” Lavras, dissertação (MS), PPGA/UFLA, 2003.

OLIVEIRA, E.R. de "A marvada pinga: trajetória histórica da produção de aguardente em Salinas, MG” Lavras, dissertação (MS), PPGA/UFLA, 2000.

PEREIRA, L. O município de Araçuaí. Belo Horizonte, Imprensa Oficial, 1969.

POSEY, D.A. "Manejo de florestas secundárias” IN RIBEIRO, B. Suma Etnológica Brasileira. Volume 1. Etnobiologia. 2a edição. Petrópolis, Vozes/Finep, 1987.

POHL, J.E. Viagem no interior do Brasil. BH/Itatiaia; São Paulo/ EDUSP, 1976.

RIBEIRO, E.M. Lembranças da terra: histórias do Mucuri e Jequitinhonha. Contagem, CEDEFES, 1996.

RIBEIRO, E.M. e GALIZONI, F.M. "Sistemas agrários, recursos naturais e migrações no alto Jequitinhonha, Minas Gerais.” In Torres, H. e Costa, 
Eduardo Magalhães Ribeiro, Flávia Maria Galizoni, Luiz Henrique Silvestre, Juliana Sena Calixto, — 1101

Thiago de Paula Assis e Eduardo Barbosa Ayres

H. (orgs) População e meio ambiente: debates e desafios. São Paulo, Senac, 2000.

RIBEIRO, E.M. e GALIZONI, F.M. "Água, população rural e políticas de gestão: o caso do vale do Jequitinhonha”. Ambiente e Sociedade. vol. VI, número 1, jan/jul 2003.

RIBEIRO, E.M., GALIZONI, F.M., ASSIS, T.P. "Os caminhos de São Paulo”. Revista Brasileira de Estudos da População. 21(2), jul/dez 2004.

RIBEIRO, E.M., GALIZONI, F.M., CALIXTO, J.S., ASSIS, T.R., AYRES, E.B., SILVESTRE, L.H. "Gestão, uso e conservação de recursos naturais em comunidades rurais do alto Jequitinhonha." Revista Brasileira de Estudos Urbanos e Regionais. V. 7, N. 2, nov 2005.

RIBEIRO, E.M.; ARAÚJO, D.P.; GALIZONI, F.M.; FREITAS, C.S.; AYRES, E.B. "Uma estimativa preliminar das receitas monetárias e não-monetárias de agricultores familiares do vale do Jequitinhonha." Fortaleza, XLIV Congresso Brasileiro de Economia e Sociologia Rural, Anais, 2006.

RIBEIRO, E.M., GALIZONI, F.M., CASTRO, B.S. "Universidade, extensão e desenvolvimento rural: uma experiência no Vale do Jequitinhonha.” Agriculturas - experiências em agroecologia. vol. 3, número 4, dezembro 2006.

SACHS, I. Ecodesenvolvimento: crescer sem destruir. São Paulo, Vértice, 1986.

SAINT-HILAIRE, A. de. Viagem pelas províncias do Rio de Janeiro e Minas Gerais. Belo Horizonte/Itatiaia; São Paulo/Edusp, 1975.

SAHLINS, M. “A primeira sociedade de afluência.” IN CARVALHO, E.A. (org.) Antropologia Econômica. São Paulo, Editora Ciências Humanas, 1978.

SANTOS, J. F. dos. Memórias do Distrito Diamantino. Belo Horizonte: Itatiaia; São Paulo: EDUSP, 1976.

SHIKI, S. O futuro do cerrado: degradação versus sustentabilidade e controle social. Rio de Janeiro. FASE, Série Cadernos Temáticos, número $2,2000$.

SILVA, M. A. M. "Quando as adorinhas são forçadas a voar” São Paulo, Centro de Estudos Migratórios, 1988.

RER, Rio de Janeiro, vol. 45, no 04, p. 1075-1102, out/dez 2007 - Impressa em novembro 2007 
SILVA, J.V.A. Igreja, escola e comunidade. Montes Claros, Editora Unimontes, 2004.

SPIX, J.B. e MARTIUS, C.F.P. von. Viagem pelo Brasil. Rio de Janeiro, Imprensa Nacional, 1938.

WIRTH, J.D. O fiel da balança: Minas Gerais na federação. Rio de Janeiro, Paz e Terra, 1982.

WOORTMANN, E.F. e WOORTMANN, K. O trabalho da terra. Brasília, Editora UnB, 1997

\section{Agradecimentos}

Os autores agradecem às organizações do alto Jequitinhonha, parceiras em projetos de pesquisa e extensão universitária: ao Centro de Agricultura Alternativa Vicente Nica (CAV), aos Sindicatos de Trabalhadores Rurais, principalmente de Chapada do Norte, Turmalina, Minas Novas e Medina, ao Instituto de Trabalhadores e Trabalhadoras do Vale do Jequitinhonha (Itavale), ao pólo regional da Federação dos Trabalhadores da Agricultura de Minas Gerais, à Comissão dos Atingidos pela Barragem de Irapé, às Escolas Famílias Agrícolas, às Cáritas diocesanas, às Emateres e prefeituras da região. Agradecem, sobretudo, às comunidades rurais, que têm sido fonte perene de aprendizado sobre os desatinos e acertos dos programas de desenvolvimento.

Recebido em março de 2006 e revisto em abril de 2007. 